\title{
Interface Engineering for Ternary Blend Polymer Solar Cells with a Heterostructured Near-IR Dye.
}

\section{AUTHOR(S):}

Xu, Huajun; Ohkita, Hideo; Tamai, Yasunari;

Benten, Hiroaki; Ito, Shinzaburo

\section{CITATION:}

Xu, Huajun ...[et al]. Interface Engineering for Ternary Blend Polymer Solar Cells with a Heterostructured Near-IR Dye.. Advanced materials 2015, 27(39): 5868-5874

\section{ISSUE DATE:}

2015-08-27

URL:

http://hdl.handle.net/2433/199677

\section{RIGHT:}

This is the peer reviewed version of the following article: Xu, H., Ohkita, H., Tamai, Y., Benten, H. and Ito, S. (2015), Interface Engineering for Ternary Blend Polymer Solar Cells with a Heterostructured Near-IR Dye. Adv. Mater., 27 5868-5874, which has been published in final form at http://dx.doi.org/10.1002/adma.201502773. This article may be used for non-commercial purposes in accordance with Wiley Terms and Conditions for Self-Archiving.; The full-text file will be made open to the public on 27 August 2016 in accordance with publisher's 'Terms and Conditions for SelfArchiving'.; この論文は出版社版でありません。引用の際には出版社版をご確認ご利用ください。; This is not the published version. Please cite only the published version. 


\section{WILEY-VCH}

DOI: $10.1002 /(($ please add manuscript number $))$

Article type: Communication

\section{Interface Engineering for Ternary Blend Polymer Solar Cells with Heterostructured Near-IR Dye}

Huajun Xu, Hideo Ohkita,* Yasunari Tamai, Hiroaki Benten, and Shinzaburo Ito

Dr. H. Xu, Dr. H. Hideo, Dr. Y. Tamai, Dr. H. Benten, Prof. S. Ito

Department of Polymer Chemistry, Graduate School of Engineering, Kyoto University, Katsura, Nishikyo-ku, Kyoto 615-8510, Japan

E-mail: ohkita@photo.polym.kyoto-u.ac.jp

Dr. H. Ohkita

Japan Science and Technology Agency (JST), PRESTO, 4-1-8 Kawaguchi Honcho, Saitama 332-0012, Japan

Keywords: interfaces, ternary blends, polymer solar cells, heterostructures, near-IR dyes

Polymer solar cells have made rapid progress in the last decade and currently have shown a power conversion efficiency (PCE) of more than $10 \%{ }^{[1,2]}$ This is mainly due to remarkable development in various low-bandgap polymers in recent years. ${ }^{[3-7]}$ For further improvement toward 15\%, it is essentially required to harvest many more photons in the solar light over the wide wavelength range from visible to near-IR region. However, it is generally difficult to cover such a wide wavelength range by only two materials of conjugated polymer and fullerene because of the limited absorption bandwidth of most conjugated polymers and small absorption of fullerene derivatives. Ternary blend solar cells have been proposed to extend the light-harvesting range from visible to near-IR region in a simple way. ${ }^{[8-27]}$

Currently, two types of ternary blend solar cells have been intensively studied to harvest more photons over the near-IR region. One is based on two donor polymers and one acceptor. $^{\left[{ }^{8-17]}\right.}$ Brabec et al. reported that the photocurrent is increased by incorporating a lowbandgap donor polymer into a binary blend of poly(3-hexylthiophene) (P3HT) and phenylC61-butyric acid methyl ester (PCBM). ${ }^{[12]}$ Later, You et al. proposed parallel-like bulk heterojunction (PBHJ) polymer solar cells based on ternary blends of two donor polymers and 


\section{WILEY-VCH}

PCBM, ${ }^{[15]}$ in analogy with the operation of parallel tandem solar cells. In PBHJ solar cells, the short-circuit current density $\left(J_{\mathrm{SC}}\right)$ is identical to the sum of those of binary subcells and the open-circuit voltage $\left(V_{\mathrm{OC}}\right)$ is in between those of binary subcells. As a result, the PCE is optimized when the weight ratio of the two donor polymers is close to $1: 1$. The other is based on one donor polymer, one acceptor, and an additional near-IR dye molecule. ${ }^{[19-27]}$ This approach is simple and versatile, and hence can be easily applied to multicolor sensitization by using two different dye molecules at the same time that have complementary absorption bands. ${ }^{[21]}$ Recently, Ratner and Marks et al. have theoretically shown that these ternary blend solar cells have the potential to exceed the efficiency limit ( 10\%) of binary blend conventional solar cells. ${ }^{[28]}$ In addition, they pointed out the challenging issues to be addressed for each ternary blend solar cell. For PBHJ solar cells, the potential advantage is limited by the thin active layer. Indeed, the thickness is as thin as 100 nm even for most state-of-the-art PBHJ cells. ${ }^{[16,17]}$ In this case, the photocurrent improvement would be limited because the absorption of the original binary blend is decreased by incorporating the third material. For dye-sensitized polymer solar cells, on the other hand, the potential advantage is limited not by the thickness but rather by a small dye loading fraction. It is typically limited to less than $10 \mathrm{wt} \%$, mostly as low as $\sim 5 \mathrm{wt} \%$, for optimized device performance. In other words, these challenging issues should be solved for further improvements toward 15\%.

Herein, we demonstrate that photovoltaic performance of ternary blend solar cells can be significantly improved by high dye loading into binary blend solar cells. More specifically, we fabricate efficient ternary blend solar cells based on P3HT and PCBM incorporating a silicon phthalocyanine derivative (SiPc) with a high loading concentration. In order to incorporate as many SiPc dye molecules as possible into the P3HT/PCBM interface selectively, we have synthesized heterostructured SiPc molecules with two different axial ligands in the direction normal to the molecular plane. One axial ligand is tri- $n$-hexylsiloxy substituent, which is compatible with P3HT with a lower surface energy, and the other is tri- 


\section{WILEY-VCH}

benzylsiloxy substituent, which is compatible with PCBM with a higher surface energy. ${ }^{\text {[29-33] }}$ In other words, the heterostructured silicon phthalocyanine derivative (SiPcBz6) would be compatible with both P3HT and PCBM and hence preferentially located at the P3HT/PCBM interface. ${ }^{[30]}$ For comparison, we also synthesized two other homostructured SiPc molecules with two identical axial ligands in the direction normal to the molecular plane. One is silicon phthalocyanine bis(tri-n-hexylsilyl oxide) (SiPc6) and the other is silicon phthalocyanine bis(tri-benzylsilyl oxide) (SiPcBz). In order to discuss how dye molecules can contribute to the photocurrent generation in ternary blend solar cells, we have studied photovoltaic properties and bimolecular recombination dynamics for ternary blend with these three SiPc molecules.

Figure 1 shows the structures of donor polymer (P3HT), acceptor fullerene (PCBM), and three SiPc dyes employed in this study. All these SiPc dyes have an intense absorption band at around $670 \mathrm{~nm}$ with a high molar absorption coefficient of $\sim 3 \times 10^{5} \mathrm{M}^{-1} \mathrm{~cm}^{-1}$ (Figure S1), indicating that these have equivalent light-harvesting property in the near-IR region. Furthermore, they exhibit large spectral overlap between the absorption band and the emission band of P3HT and hence have potential equally for efficient long-range Förster energy transfer in ternary blends as described below. Their HOMO and LUMO levels were estimated to be $\sim 5.4 \mathrm{eV}$ and $\sim 3.5 \mathrm{eV}$, respectively, by cyclic voltammetry (Figure 1 ). In other words, axial ligands employed here have negligible impact on electronic structures of these three SiPc dyes. On the other hand, the HOMO levels of P3HT and PCBM in solid state were estimated to be $4.7 \mathrm{eV}$ and $6.1 \mathrm{eV}$, respectively, by photoemission yield spectroscopy, which are consistent with previous reports. ${ }^{[34-37]}$ The LUMO level was evaluated to be $3.8 \mathrm{eV}$ for PCBM by the cyclic voltammetry and to be $2.7 \mathrm{eV}$ for P3HT from the optical bandgap and the HOMO level. Thus, as shown in the figure, all three ternary blends of P3HT, PCBM, and SiPc dyes exhibit cascaded energy structures both in the HOMO and LUMO levels (PCBM < SiPc dyes $<$ P3HT) with offset energies of $>0.2 \mathrm{eV}$, which are sufficient for the charge 


\section{WILEY-VCH}

separation. This is one of the absolute requirements for efficient dye sensitization at longer wavelength region. In summary, all these three SiPc dye molecules have equivalent potential for the light-harvesting, the exciton-harvesting, and the charge generation efficiency in ternary blend films if blend morphology is the same.

Figure 2 shows the absorption spectrum of SiPcBz6 and the photoluminescence (PL) spectrum of a P3HT neat film. As mentioned above, the absorption spectrum of SiPcBz6 is well overlapped with the PL spectrum of P3HT, indicating efficient long-range Förster energy transfer from P3HT excitons to SiPcBz6 dye molecules. The same is true for the other dyes (Figure S1). Indeed, we previously revealed by transient absorption spectroscopy that P3HT excitons in P3HT/PCBM/SiPc6 ternary blends are efficiently collected to SiPc6 molecules by long-range Förster energy transfer. ${ }^{[38]}$ We note that no emission from dye molecules are observed for P3HT/PCBM/SiPc ternary blends (Figure S2). This is because such energy transfer is followed by efficient charge separation as reported previously. ${ }^{[38]}$ As shown in the inset of Figure 2, the PL quenching efficiency was 90\% for P3HT/PCBM binary blends, which is consistent with the previous reports. ${ }^{[20,38,39]}$ This finding indicates that $\sim 10 \%$ of P3HT excitons are lost during the exciton diffusion. The PL quenching efficiency abruptly increased to $\sim 95 \%$ for all the dyes at a dye loading of $5 \mathrm{wt} \%$, and then was saturated for $\mathrm{SiPcBz}$ at $>5 \mathrm{wt} \%$ while still increased up to $>98 \%$ for SiPcBz6 at $15 \mathrm{wt} \%$. In other words, almost all the P3HT excitons are quenched in P3HT/PCBM/SiPcBz6 ternary blends. Such an almost 100\% PL quenching is indicative of the efficient long-range Förster energy transfer followed by the charge separation because no morphological change is induced by the dye addition as described later. Although the error bars are not negligible, the maximum PL quenching efficiency is dependent upon the dye molecules in spite of the similar spectral overlap as mentioned before. This is indicative of different dye distribution in ternary blend films. 


\section{WILEY-VCH}

To examine the blend morphology in the presence or absence of dye molecules, we measured the AFM images and the absorption spectra of a binary blend control film and three different ternary blend films. As shown in Figure S3, P3HT fibrils were clearly observed for all the blend films at an optimized dye concentration (5 wt\% SiPc6, 15 wt\% SiPcBz6, and 5 $\mathrm{wt} \% \mathrm{SiPcBz}$ ). These fibril structures were almost the same in spite of the presence or absence of dye molecules, suggesting that dye loading does not significantly disturb P3HT crystallization or phase-separated structures on a scale of tens of nanometers. In order to examine not only surface but also bulk morphology, we discuss how dye loading impacts on the crystallization of P3HT on the basis of the absorption spectra of ternary blends with various dye concentrations from 0 to $30 \mathrm{wt} \%$. As reported previously, ${ }^{[40,41]}$ the crystallinity of P3HT can be evaluated from the vibronic absorption bands, which has a good correlation with that evaluated from XRD measurements. For comparison, the absorbance is normalized at $470 \mathrm{~nm}$ where the absorption of dye molecules is negligible (Figure S4). For SiPcBz6, as shown in Figure 3a, the absorbance of the dye absorption band at around $680 \mathrm{~nm}$ monotonically increased with increasing dye concentrations up to $30 \mathrm{wt} \%$. For SiPc6, it monotonically increased with increasing dye concentrations up to $20 \mathrm{wt} \%$ and then was saturated at $30 \mathrm{wt} \%$. For SiPcBz, it increased sublinearly at low concentrations and then significantly decreased at $30 \mathrm{wt} \%$. These findings suggests that dye aggregation is negligible for SiPcBz6 but substantial for SiPc6 and SiPcBz at high dye concentrations. On the other hand, the absorption band from 400 to $650 \mathrm{~nm}$ is ascribed to P3HT. In particular, the absorption shoulder at around $610 \mathrm{~nm}$ is characteristic of $\pi-\pi$ stacking in P3HT crystalline domains, which is overlapped with the $0-1$ vibrational absorption band of SiPc dye molecules. As shown in Figure 3b, the absorption dependence at around $610 \mathrm{~nm}$ was consistent with that observed for the dye absorption at around $680 \mathrm{~nm}$, suggesting that the increase in the absorbance at $610 \mathrm{~nm}$ is mainly due to the $0-1$ vibrational absorption band of SiPc dye molecules. In other words, the absorption of P3HT remains the same, suggesting that P3HT 


\section{WILEY-VCH}

crystallization is not disturbed by the dye loading. This is consistent with no morphological change observed for the AFM images.

Figure 4 shows the photovoltaic device parameters of P3HT/PCBM/SiPc ternary blend solar cells with various dye loading concentrations under AM 1.5G simulated solar irradiation at an intensity of $100 \mathrm{~mA} \mathrm{~cm}{ }^{-2}$. These parameters are averaged for at least 18 devices. Note that the $J-V$ characteristics and external quantum efficiency (EQE) spectra of typical ternary blend devices are shown in Figure 4 and Figure 5 and the best photovoltaic parameters are summarized in Table S1. As shown in Figure 4a, the $J_{\mathrm{SC}}$ reached a maximum of $\sim 11.5 \mathrm{~mA} \mathrm{~cm}^{-2}$ at $5 \mathrm{wt} \%$ for SiPcBz and SiPc6, and $\sim 13 \mathrm{~mA} \mathrm{~cm}^{-2}$ at $15 \mathrm{wt} \%$ for SiPcBz6. As shown in Figure $4 \mathrm{~b}$, the $V_{\mathrm{OC}}$ monotonically decreased from 0.55 to $0.53 \mathrm{~V}$ for $\mathrm{SiPcBz}$, showed a maximum of $\sim 0.58 \mathrm{~V}$ at $10 \mathrm{wt} \%$ and then decreased to $0.52 \mathrm{~V}$ for SiPc6, and monotonically increased from 0.55 to $\sim 0.6 \mathrm{~V}$ for SiPcBz6. The fill factor (FF), as shown in Figure 4c, monotonically decreased from 0.63 to $\sim 0.55$ for all the SiPc dyes: most rapidly for SiPcBz, modestly for SiPc6, and most gradually for SiPcBz6. Consequently, as shown in Figure 4d, the overall PCE was 3.6\% at 5 wt\% for SiPcBz, which is comparable to that of the P3HT/PCBM control binary cell, while it was improved to $4 \%$ at 5 wt $\%$ for SiPc6, and $4.4 \%$ at $10-15$ wt\% for SiPcBz6. As shown in Figure 5, P3HT/PCBM/SiPcBz6 ternary cells exhibit the best PCE of $4.8 \%$ at $15 \mathrm{wt} \%$ with an EQE of more than $60 \%$ at the dye absorption while P3HT/PCBM/SiPc6 and P3HT/PCBM/SiPcBz ternary cells exhibit the best PCE at 5 wt\% with an EQE of less than $40 \%$ at the dye absorption. This is primarily due to the improvement in $J_{\mathrm{SC}}$ and additionally due to $V_{\mathrm{OC}}$ at high loading concentrations. As shown in Figure $5 \mathrm{~b}$, the increase in $J_{\mathrm{SC}}$ is due to the improvement not only at the dye absorption band but also at the P3HT absorption band. These findings suggest that SiPcBz6 molecules can be selectively located at the P3HT/PCBM interface even at higher loading concentrations up to 30 wt\% while SiPc6 and SiPcBz would overflow to other domains at high loading concentrations as described later. 


\section{WILEY-VCH}

We measured bimolecular recombination dynamics to discuss location of dye molecules in ternary blend films. As shown in Figure S7, all the decay dynamics were well fitted with an empirical power-law equation $n(t)=n_{0} /(1+a t)^{\alpha}$, which is consistent with our previous result. ${ }^{[42]}$ This power-law decay is indicative of the bimolecular recombination in energetically disordered materials. ${ }^{[43,44]}$ From the decay parameters $a$ and $\alpha$ obtained by the fitting, the charge carrier lifetime $\tau=(a \alpha)^{-1}$ is estimated to be $5.2 \mu$ s for P3HT/PCBM binary blends under the excitation intensity employed in this study, which is consistent with that evaluated by transient photovoltage/photocurrent and charge extraction measurements. ${ }^{[45]}$ As summarized in Table 1, the carrier lifetime is longer in ternary blends than in binary blends, and longest (15.6 $\mu \mathrm{s})$ in P3HT/PCBM/SiPcBz6 ternary blend films. Recently, Friend et al. have demonstrated that such energy-level cascades can suppress the bimolecular recombination by using triple-layered all polymer solar cells. ${ }^{[46]}$ Thus, these findings indicate that dye molecules are selectively located at P3HT/PCBM interface and hence can effectively suppress the bimolecular recombination in ternary blend films.

Finally, we discuss the location of dye molecules in ternary blend films. At a low dye concentration of $5 \mathrm{wt} \%$, as shown in Figure 4, all the dye molecules do contribute to the photocurrent generation effectively. This finding clearly shows that the majority of dye molecules are located at the P3HT/PCBM interface. As discussed previously, ${ }^{[20]}$ if dye molecules were isolated in P3HT or PCBM domains, they could not contribute to the photocurrent generation at all. Indeed, we found by the transient absorption study that upon the photoexcitation of SiPc6 isolated in P3HT domains, all P3HT polarons and SiPc6 anions generated geminately recombine with a time constant of 2 ns. ${ }^{[38]}$ For P3HT/PCBM/SiPc6 ternary blends, on the other hand, such geminate recombination is negligible but instead SiPc6 anions are rapidly transferred to PCBM domains. In other words, all the SiPc6 molecules should be contact with P3HT and PCBM at the same time, that is, located at the interface of 


\section{WILEY-VCH}

P3HT/PCBM. This would be true for the other dyes at a low dye loading. At higher dye concentrations of $10-20 \mathrm{wt} \%$, the $J_{\mathrm{SC}}$ decreased for SiPc6 and SiPcBz while it still increased for SiPcBz6. On the other hand, the dye absorption increased linearly for all the dyes. Thus, dye aggregation is still negligible but some of SiPc6 and SiPcBz molecules would be located not at the interface but in preferred domains. Most probably, SiPc6 and SiPcBz molecules are likely to be located at P3HT and PCBM domains respectively, because hexyl and benzyl ligands prefer to P3HT and PCBM respectively. ${ }^{[30]}$ At more higher dye concentrations of $>20$ wt $\%$, the $J_{\text {SC }}$ decreased and the dye absorption decreased or was saturated for SiPc6 and SiPcBz, suggesting dye aggregations. In contrast, the SiPcBz6 absorption still increased linearly, suggesting negligible dye aggregations even at $30 \mathrm{wt} \%$. The saturated $J_{\mathrm{SC}}$ at $>15$ wt\% is simply because the absorption is saturated as shown in Figure S4. Furthermore, the carrier lifetime is the longest in P3HT/PCBM/SiPcBz6 blends, suggesting that bimolecular recombination is most effectively suppressed because of the presence of SiPcBz6 at the P3HT/PCBM interface. This is consistent with the slight increase in $V_{\text {OC }}$ for P3HT/PCBM/SiPcBz6 solar cells as shown in Figure 4. As reported previously, VoC is effectively increased by such cascaded energy structures formed at the heterojunction. ${ }^{[46,47]}$ In contrast, no distinct increase in $V_{\mathrm{OC}}$ is observed for SiPc6 even at high loading concentrations as reported previously. ${ }^{[48]}$ This is because interfacial coverage of dye molecules is not enough to suppress the bimolecular recombination effectively. We therefore conclude that SiPcBz6 molecules are most likely to be located at the P3HT/PCBM interface even at high loading concentrations. More precisely, SiPcBz6 molecules are well mixed with PCBM in the P3HT disordered amorphous phase that is located at the interface of P3HT crystalline and PCBM aggregated domains. ${ }^{[38]}$ Such interfacial location is most probably because SiPcBz6 molecules have hexyl and benzyl ligands at the same time, which prefer to P3HT and PCBM respectively at the interface. 


\section{WILEY-VCH}

In conclusion, we have shown that the interface engineering is of particular importance for dye sensitization in ternary blend solar cells. The heterostructured SiPcBz6 is suitable for the selective loading to the interface with high dye concentrations and hence can boost the photovoltaic performance by $\sim 30 \%$. This approach should be applicable to silicon naphthalocyanine derivatives ${ }^{[21,27]}$ and hence useful for multi-colored sensitization for further improvements. Considering the saturated absorption of the SiPc dyes at high loadings, the light-harvesting range can be expanded more effectively by employing dyes with a wider absorption band but a smaller absorption coefficient than SiPc dyes.

\section{Experimental Section}

Synthesis of SiPcBz6: A heterostructured SiPcBz6 dye was synthesized by the following three step reactions (Figure S8).

$1\left[\mathrm{CH}_{3} \mathrm{SiPcOSi}\left(n-\mathrm{C}_{6} \mathrm{H}_{13}\right)_{3}\right]$ : A mixture of hydroxyl methyl silicon phthalocyanine $\left(\mathrm{CH}_{3} \mathrm{SiPcOH}\right)(100 \mathrm{mg})$, chlorotrihexylsilane $(250 \mu \mathrm{L})$, and dry pyridine $(10 \mathrm{~mL})$ was refluxed for $5 \mathrm{~h}$. After the solution obtained had been allowed to cool, the solvent was evaporated and the chloroform was added to the residue. The solution was washed with saturated $\mathrm{NaCl}$ solution, and then dried over $\mathrm{MgSO}_{4}$. After evaporation of the solvent, the residue was purified by silica gel column chromatography (toluene/hexane $=1 / 1(\mathrm{v} / \mathrm{v})$ as eluent) to afford $\mathbf{1}(80 \mathrm{mg})$ as a green solid (yield $=54 \%) . \mathrm{UV}$-visible (toluene): $\lambda_{\max } 673 \mathrm{~nm}$ $\left(\varepsilon=2.6 \times 10^{5} \mathrm{M}^{-1} \mathrm{~cm}^{-1}\right) .{ }^{1} \mathrm{H}$ NMR (400 MHz, $\left.\mathrm{CDC}_{13}\right): \delta=9.31(\mathrm{~m}, \alpha-\mathrm{Pc}, 8 \mathrm{H}), 8.25(\mathrm{~m}, \beta-\mathrm{Pc}$, 8H), $0.72\left(\mathrm{~m}, \varepsilon-\mathrm{CH}_{2}, 6 \mathrm{H}\right), 0.58\left(\mathrm{t}, \mathrm{CH}_{3}, 9 \mathrm{H}\right), 0.22\left(\mathrm{~m}, \delta-\mathrm{CH}_{2}, 6 \mathrm{H}\right),-0.15\left(\mathrm{~m}, \gamma-\mathrm{CH}_{2}, 6 \mathrm{H}\right)$, $-1.45\left(\mathrm{~m}, \beta-\mathrm{CH}_{2}, 6 \mathrm{H}\right),-2.61\left(\mathrm{~m}, \alpha-\mathrm{CH}_{2}, 6 \mathrm{H}\right),-6.40\left(\mathrm{~s}, \mathrm{SiPcCH}_{3}, 3 \mathrm{H}\right)$.

2 [HOSiPcOSi $\left.\left(n-\mathrm{C}_{6} \mathrm{H}_{13}\right)_{3}\right]$ : A stirred mixture of $\mathbf{1}(100 \mathrm{mg})$, triethylamine $(1 \mathrm{~mL})$, distillated water (0.2 mL), and toluene (200 mL) was irradiated with visible light (500-W tungsten lamp) for 30 min. The solution color turned from green to blue-green. After the solution obtained 


\section{WILEY-VCH}

had been allowed to cool, the solvent was evaporated and the residue was added to hexane ( 2 $\mathrm{mL}$ ). The resulting suspension was filtered, and the solid was washed with hexane. The solid obtained was further dissolved with $\mathrm{CH}_{2} \mathrm{Cl}_{2}(20 \mathrm{~mL})$ and filtered. After evaporation of the filtrate, the residue was dissolved in $\mathrm{CH}_{2} \mathrm{Cl}_{2}(1 \mathrm{~mL})$, precipitated from the solution with $n$ pentane ( $5 \mathrm{~mL}$ ), recovered by filtration, washed with $n$-pentane, vacuum-dried, and weighed (blue solid, $51 \mathrm{mg}$, yield = 50\%). ${ }^{1} \mathrm{H}$ NMR (400 MHz, CDC1 13$): \delta=9.40$ (m, 3,6-Pc, 8H), 8.40 (m, 4,5-Pc, 8H), 0.89 (m, $\left.\varepsilon-\mathrm{CH}_{2}, 6 \mathrm{H}\right), 0.80\left(\mathrm{t}, \mathrm{CH}_{3}, 9 \mathrm{H}\right), 0.40\left(\mathrm{~m}, \delta-\mathrm{CH}_{2}, 6 \mathrm{H}\right), 0.05$ (m, $\left.\gamma-\mathrm{CH}_{2}, 6 \mathrm{H}\right),-1.25\left(\mathrm{~m}, \beta-\mathrm{CH}_{2}, 6 \mathrm{H}\right),-2.40\left(\mathrm{~m}, \alpha-\mathrm{CH}_{2}, 6 \mathrm{H}\right)$.

3 [(( $\left.\left.\left.\mathrm{C}_{6} \mathrm{H}_{5}\right) \mathrm{CH}_{2}\right)_{3} \mathrm{SiOSiPcOSi}\left(n-\mathrm{C}_{6} \mathrm{H}_{13}\right)_{3}, \mathrm{SiPcBz} 6\right]$ : A mixture of 2 (72 mg), chlorotribenzylsilane (75 mg), and dry pyridine (10 mL) was refluxed for $4 \mathrm{~h}$. After the solution obtained had been allowed to cool, the solvent was evaporated and the chloroform was added to the residue. The solution was washed with saturated $\mathrm{NaCl}$ solution, and then dried over $\mathrm{MgSO}_{4}$. After evaporation of the solvent, the residue was purified by silica gel column chromatography (dichloromethane/hexane $=1 / 1(\mathrm{v} / \mathrm{v})$ as eluent) to afford $\mathbf{3}(32 \mathrm{mg})$ as a bluish-green solid (yield $=33 \%)$. UV-visible (toluene): $\lambda_{\max } 672 \mathrm{~nm}\left(\varepsilon=3.0 \times 10^{5} \mathrm{M}^{-1}\right.$ $\mathrm{cm}^{-1}$ ). ${ }^{1} \mathrm{H}$ NMR (400 MHz, CDC1 13$): \delta=9.60$ (m, 3,6-Pc, 8H), 8.30 (m, 4,5-Pc, 8H), 6.45 (m, 4-Ph, 3H, $\mathrm{CH}_{2}\left(\mathrm{C}_{6} \mathrm{H}_{5}\right)$ chain), 6.30 (m, 3,5-Ph, 6H, $\mathrm{CH}_{2}\left(\mathrm{C}_{6} \mathrm{H}_{5}\right)$ chain), 4.90 (m, 2,6-Ph, 6H, $\mathrm{CH}_{2}\left(\mathrm{C}_{6} \mathrm{H}_{5}\right)$ chain), 0.79 (m, $\varepsilon-\mathrm{CH}_{2}, 6 \mathrm{H}, n-\mathrm{C}_{6} \mathrm{H}_{13}$ chain), 0.62 (t, $\mathrm{CH}_{3}, 9 \mathrm{H}, n-\mathrm{C}_{6} \mathrm{H}_{13}$ chain), 0.32 (m, $\delta-\mathrm{CH}_{2}, 6 \mathrm{H}, n-\mathrm{C}_{6} \mathrm{H}_{13}$ chain), -0.08 (m, $\gamma-\mathrm{CH}_{2}, 6 \mathrm{H}, n-\mathrm{C}_{6} \mathrm{H}_{13}$ chain), -1.02 (m, $\mathrm{CH}_{2}, 6 \mathrm{H}$, $\mathrm{CH}_{2}\left(\mathrm{C}_{6} \mathrm{H}_{5}\right)$ chain), -1.35 (m, $\beta-\mathrm{CH}_{2}, 6 \mathrm{H}, n-\mathrm{C}_{6} \mathrm{H}_{13}$ chain), -2.55 (m, $\alpha-\mathrm{CH}_{2}, 6 \mathrm{H}, n-\mathrm{C}_{6} \mathrm{H}_{13}$ chain).

$\mathrm{H}^{1}$ NMR spectra of the materials 1, 2, and 3 are summarized in Figure S9.

Sample fabrication. The quartz, glass, and ITO-substrates were cleaned by ultrasonication in toluene, acetone, and ethanol each for $15 \mathrm{~min}$, dried with $\mathrm{N}_{2}$, and cleaned with a $\mathrm{UV}-\mathrm{O}_{3}$ cleaner for $30 \mathrm{~min}$. For device performance measurements, poly(3,4ethylenedioxythiophene):poly(4-styrenesulfonate) (PEDOT:PSS; H. C. Starck, PH500) was 


\section{WILEY-VCH}

spin-coated onto the cleaned ITO-coated substrate at $3000 \mathrm{rpm}$ and baked at $140{ }^{\circ} \mathrm{C}$ for 10 min in air. Subsequently, an active layer ( 220 nm) of P3HT/PCBM/SiPc blends was spincoated from $o$-dichlorobenzene solution on the PEDOT:PSS coated ITO substrates at $600 \mathrm{rpm}$ for $60 \mathrm{~s}$ in a nitrogen atmosphere. Then, the wet film was dried in covered glass petri dishes for $60 \mathrm{~min}$. Finally, the $\mathrm{Ca} / \mathrm{Al}$ electrode $(20 / 70 \mathrm{~nm})$ was thermally deposited on top of the active layer at $2.5 \times 10^{-4} \mathrm{~Pa}$. The blend solution was prepared as follows: P3HT (Plextronics, regioregularity $>98 \%, M_{\mathrm{n}}=\sim 45,000-65,000 \mathrm{~g} \mathrm{~mol}^{-1}$ ) and PCBM (Frontier Carbon) were dissolved in o-dichlorobenzene (20 and $20 \mathrm{mg} \mathrm{mL}^{-1}$ ), the solution was stirred at $40{ }^{\circ} \mathrm{C}$ overnight, and then dye molecules were dissolved in the solution at room temperature. For PL quenching measurements, P3HT/PCBM/SiPc blend films were spin-coated on the cleaned quartz glass from o-dichlorobenzene solution in the same way as the device fabrication. Measurements. Electrochemical properties of dye molecules were examined by cyclic voltammetry. The cyclic voltammograms were measured in a mixed solution of $o$ dichlorobenzene and acetonitrile (4:1 v/v) dried by molecular sieves (4A 1/16, Nacalai Tesque) containing $0.1 \mathrm{M}$ tetrabutylammonium perchlorate (Wako, TBAP) with a potentiostat (Perkin-Elmer, 273A). The reference electrode was $\mathrm{Ag} / \mathrm{Ag}^{+}$in $0.1 \mathrm{M}$ TBAP in acetonitrile and the counter electrode was a Pt wire. The electrolyte solution was deoxygenated by bubbling with argon for 30 min before the measurement.

The ionization potential of P3HT, PCBM, and dye neat films was measured with a photoelectron yield spectrometer (Riken Keiki, AC-3). All the neat films (ca. $60 \mathrm{~nm}$ ) were fabricated by spin-coating from each chlorobenzene solution on the PEDOT:PSS-coated ITO substrate. The threshold energy for the photoelectron emission was estimated on the basis of the cubic root of the photoelectron yield plotted against the incident photon energy as reported previously. ${ }^{[49,50]}$

Absorption and PL spectra of the blend films were measured with a spectrophotometer (Hitachi, UV-3500) and a fluorophotometer (Hitachi, F-4500), respectively. 


\section{WILEY-VCH}

The current density-voltage $(J-V)$ characteristics were measured with a DC voltage and current source/monitor (Advantest, R6243) in the dark and under AM1.5G simulated solar illumination at $100 \mathrm{~mW} \mathrm{~cm}{ }^{-2}$. The light intensity was corrected with a calibrated silicon photodiode reference cell (Bunkoh-Keiki, BS-520). The EQE spectra were measured with a digital electrometer (Advantest, R8252) under monochromatic light illumination from a 500W xenon lamp (Thermo Oriel, 66921) with optical cut filters and a monochromator (Thermo Oriel, Cornerstone). The illumination was carried out from the ITO side under nitrogen atmosphere at room temperature. At least 18 devices were fabricated to ensure the reproducibility of the device performance.

Top surface morphology was measured in tapping mode with atomic force microscope (Shimadzu, SPM-9600) by using a high resolution cantilever (MikroMasch, Hi’Res-C14/Cr$\mathrm{Au}$ ) with a force constant of $\sim 5 \mathrm{~N} \mathrm{~m}^{-1}$ and a resonance frequency of $160 \mathrm{kHz}$.

Microsecond transient absorption data were collected with a highly sensitive microsecond transient absorption system. A dye laser (Photon Technology International Inc., GL-301) pumped by a nitrogen laser (Photon Technology International Inc., GL-3300) was used as an excitation source. The excitation wavelength was set at $610 \mathrm{~nm}$ with a fluence of $0.3-0.6 \mu \mathrm{J}$ $\mathrm{cm}^{-2}$. A tungsten lamp (Thermo Oriel, 66997) with an intensity controller (Thermo Oriel, 66950) was used as a probe light source. The sample films were sealed in a quartz cuvette purged with nitrogen. Note that the transient absorption data were highly reproducible even after the several times measurements. In other words, the laser irradiation had negligible effects on the sample degradation at least under this experimental condition. Details of transient absorption measurements are described elsewhere. ${ }^{[42]}$

\section{Supporting Information}

Supporting Information is available from the Wiley Online Library or from the author.

\section{Acknowledgements}




\section{WILEY-VCH}

This work was partly supported by the FIRST program (Development of Organic Photovoltaics toward a Low-Carbon Society: Pioneering Next Generation Solar Cell Technologies and Industries via Multi-manufacturer Cooperation) and the JST PRESTO program (Photoenergy Conversion Systems and Materials for the Next Generation Solar Cells).

Received: ((will be filled in by the editorial staff))

Revised: ((will be filled in by the editorial staff)) Published online: ((will be filled in by the editorial staff))

[1] M. A. Green, K. Emery, Y. Hishikawa, W. Warta, E. D. Dunlop, Prog. Photovolt.: Res. Appl. 2015, 231.

[2] Y. Liu, J. Zhao, Z. Li, C. Mu, W. Ma, H. Hu, K. Jiang, H. Lin, H. Ade, H. Yan, Nat. Commun. 2014, 5, 5293.

[3] E. Bundgaard, F. C. Krebs, Sol. Energy Mater. Sol. Cells 2007, 91, 954.

[4] Y. Liang, L. Yu, Acc. Chem. Res. 2010, 43, 1227.

[5] P. M. Beaujuge, J. M. J. Fréchet, J. Am. Chem. Soc. 2011, 133, 20009.

[6] G. Li, R. Zhu, Y. Yang, Nat. Photon. 2012, 6, 153.

[7] Y. F. Li, Acc. Chem. Res. 2012, 45, 723.

[8] Y. -C. Chen, C. -Y. Hsu, R. Y. -Y. Lin, K. -C. Ho, J. T. Lin, ChemSusChem 2013, 6, 20.

[9] T. Ameri, P. Khoram, J. Min, C. J. Brabec, Adv. Mater. 2013, 25, 4245.

[10] F. Liu, Y. Gu, X. Shen, S. Ferdous, H. -W. Wang, T. P. Russell, Prog. Polym. Sci. 2013, 38, 1990.

[11] L. Yang, L. Yan, W. You, J. Phys. Chem. Lett. 2013, 4, 1802.

[12] M. Koppe, H. -J. Egelhaaf, G. Dennler, M. C. Scharber, C. J. Brabec, P. Schilinsky, C. N. Hoth, Adv. Funct. Mater. 2010, 20, 338.

[13] T. Ameri, J. Min, N. Li, F. Machui, D. Baran, M. Forster, K. J. Schottler, D. Dolfen, U. Scherf, C. J. Brabec, Adv. Energy Mater. 2012, 2, 1198. 


\section{WILEY-VCH}

[14] T. Ameri, T. Heumüller, J. Min, N. Li, G. Matt, U. Scherf, C. J. Brabec, Energy Environ. Sci. 2013, 6, 1796.

[15] L. Yang, H. Zhou, S. C. Price, W. You, J. Am. Chem. Soc. 2012, 134, 5432.

[16] L. Lu, T. Xu, W. Chen, E. S. Landry, L. Yu, Nat. Photon. 2014, 8, 716.

[17] Y. Yang, W. Chen, L. Dou, W. -H. Chang, H. -S. Duan, B. Bob, G. Li, Y. Yang, Nat. Photon. 2015, 9, 190.

[18] P. P. Khlyabich, B. Burkhart, B. C. Thompson, J. Am. Chem. Soc. 2011, 133, 14534.

[19] J. Peet, A. B. Tamayo, X. -D. Dang, J. H. Seo, T. -Q. Nguyen, Appl. Phys. Lett. 2008, 93, 163306.

[20] S. Honda, T. Nogami, H. Ohkita, H. Benten, S. Ito, ACS Appl. Mater. Interfaces 2009, $1,804$.

[21] S. Honda, H. Ohkita, H. Benten, S. Ito, Chem. Commun. 2010, 46, 6596.

[22] K. Kubo, K. Watanabe, R. Nishiyabu, R. Hata, A. Murakami, T. Shoda, H. Ota, Org. Lett. 2011, 13, 4574.

[23] S. Yamamoto, M. Kimura, ACS Appl. Mater. Interfaces 2013, 5, 4367.

[24] J. -S. Huang, T. Goh, X. Li, M. Y. Sfeir, E. A. Bielinski, S. Tomasulo, M. L. Lee, N. Hazari, A. D. Taylor, Nat. Photon. 2013, 7, 479.

[25] H. Xu, T. Wada, H. Ohkita, H. Benten, S. Ito, Electrochim. Acta 2013, 100, 214.

[26] Y. Wang. B. Zheng, Y. Tamai, H. Ohkita, H. Benten, S. Ito, J. Electrochem. Soc. 2014, 161, D3093.

[27] B. Lim, J. T. Bloking, A. Ponec, M. D. McGehee, A. Sellinger, ACS Appl. Mater. Interfaces 2014, 6, 6905.

[28] B. M. Savoie, S. Dunaisky, T. J. Marks, M. A. Ratner, Adv. Energy Mater. 2015, 5, 1400891.

[29] S. Honda, H. Ohkita, H. Benten, S. Ito, Adv. Energy Mater. 2011, 1, 588.

[30] H. Xu, T. Wada, H. Ohkita, H. Benten, S. Ito, Sci. Rep. 2015, 5, 9321. 


\section{WILEY-VCH}

[31] L. Ronbinson, J. Isaksson, N. D. Robinson, M. Berggren, Surf. Sci. Lett. 2006, 600, L148.

[32] J. Jaczewska, I. Raptis, A. Budkowski, D. Goustouridis, J. Raczkowska, E. Pamuła, A. Bernasik, J. Rysz, Synth. Met. 2007, 157, 726.

[33] S. Nilsson, A. Bernasik, A. Budkowski, E. Moons, Macromolecules 2007, 40, 8291.

[34] K. Kanai, T. Miyazaki, H. Suzuki, M. Inaba, Y. Ouchi, K. Seki, Phys. Chem. Chem. Phys. 2010, 12, 273.

[35] S. Yamamoto, A. Orimo, H. Ohkita, H. Benten, S. Ito, Adv. Energy Mater. 2012, 2, 229.

[36] K. Akaike, K. Kanai, H. Yoshida, J. Tsutsumi, T. Nishi, N. Sato, Y. Ouchi, K. Seki, J. Appl. Phys. 2008, 104, 023710.

[37] S. Yamamoto, H. Ohkita, H. Benten, S. Ito, Adv. Funct. Mater. 2012, 22, 3075.

[38] S. Honda, S. Yokoya. H. Ohkita. H. Benten, S. Ito, J. Phys. Chem. C 2011, 115, 11306.

[39] A. L. Ayzner, D. D. Wagner, C. J. Tassone, S. H. Tolbert, B. J. Schwartz, J. Phys. Chem. C 2008, 112, 18711.

[40] U. Zhokhavets, T. Erb, G. Gobsch, M. Al-Ibrahim, O. Ambacher, Chem. Phys. Lett. 2006, 418, 347.

[41] F. -C. Wu, Y. -C. Huang, H. -L. Cheng, W. -Y. Chou, F. -C. Tang, J. Phys. Chem. C 2011, 115, 15066.

[42] J. Guo, H. Ohkita, S. Yokoya, H. Benten, S. Ito, J. Am. Chem. Soc. 2010, 132, 9631.

[43] J. Nelson, Phys. Rev. B 2003, 67, 155209.

[44] M. Tachiya, K. Seki, Phys. Rev. B 2010, 82, 085201.

[45] D. Credgington, J. R. Durrant, J. Phys. Chem. Lett. 2012, 3, 1465.

[46] Z. -K. Tan, K. Johnson, Y. Vaynzof, A. A. Bakulin, L. -L. Chua, P. K. Ho, R. H. Friend, Adv. Mater. 2013, 25, 4131.

[47] S. Sista, Y. Yao, Y. Yang, M. L. Tang, Z. Bao, Appl. Phys. Lett. 2007, 91, 223508. 


\section{WILEY-VCH}

[48] H. Xu, H. Ohkita, H. Benten, S. Ito, Jpn. J. Appl. Phys. 2014, 53, $01 \mathrm{AB} 10$.

[49] M. Kochi, Y. Harada, T. Hirooka, H. Inokuchi, Bull. Chem. Soc. Jpn. 1970, 43, 2690.

[50] K. Seki, K. Kanai, Mol. Cryst. Liq. Cryst. 2006, 455, 145. 


\section{WILEY-VCH}

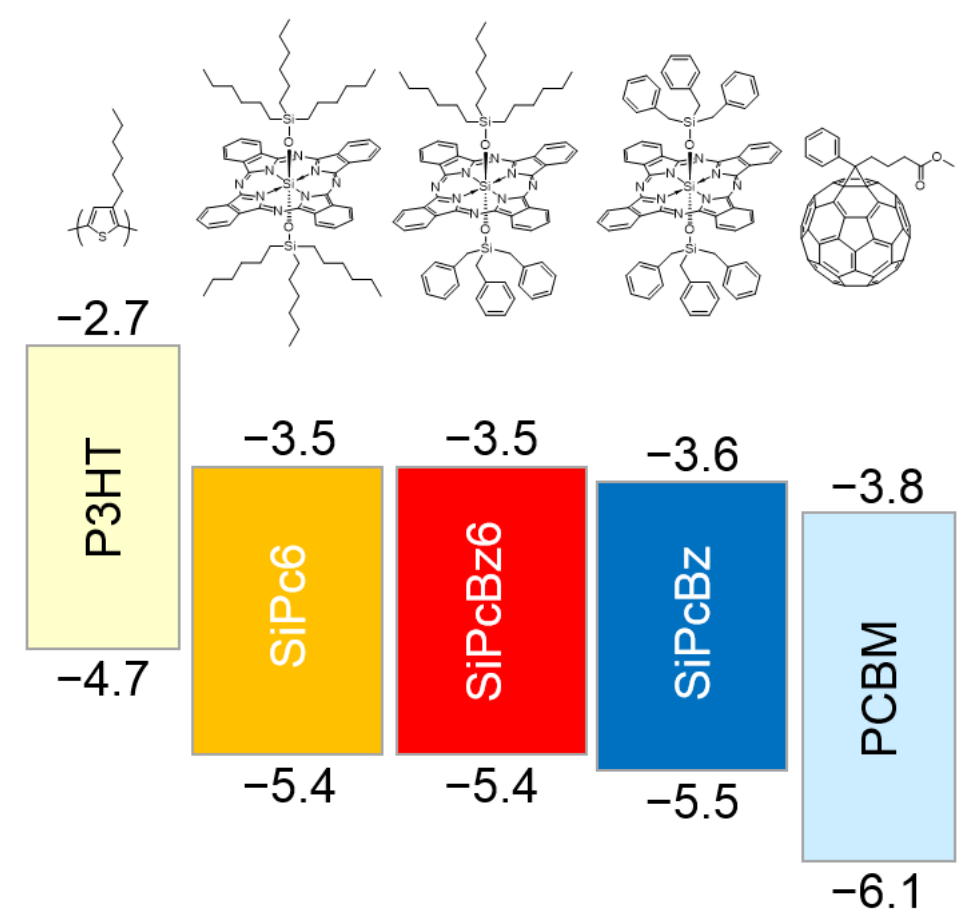

Figure 1. Chemical structures and energy diagram of materials employed in this study: P3HT, SiPc6, SiPcBz6, SiPcBz, and PCBM in order from left to right. The figures represent the HOMO (lower) and LUMO (upper) energy in electron volts. 


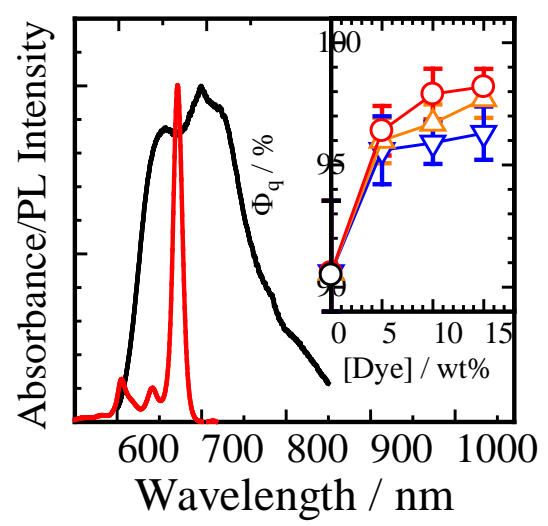

Figure 2. Absorption spectrum of SiPcBz6 (red line) and photoluminescence (PL) spectrum of P3HT (black line). The inset shows the PL quenching efficiency of ternary blend films: SiPc6 (orange triangles), SiPcBz6 (red circles), SiPcBz (blue inverse triangles), and no dye (black circle). The error bars in the inset represent the standard deviation. 
WILEY-VCH

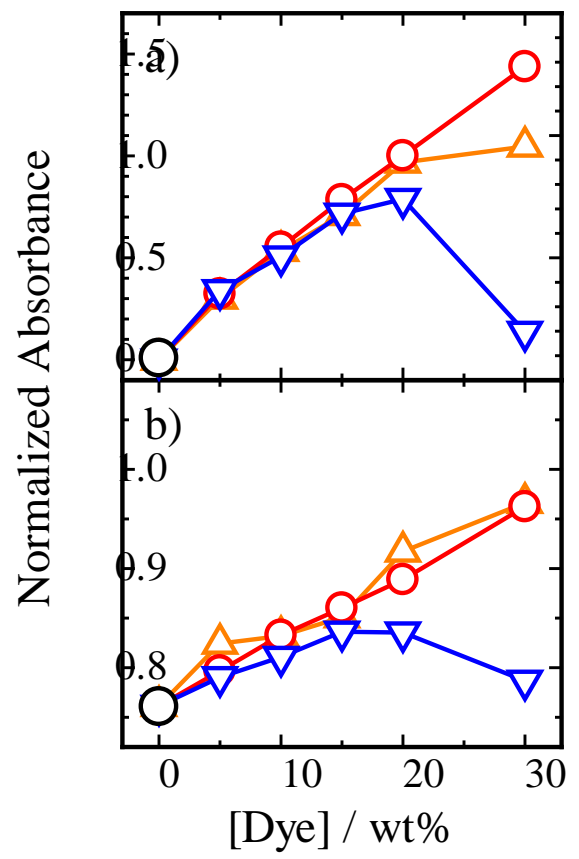

Figure 3. Normalized absorbance of P3HT/PCBM/SiPc ternary blend films with different dye loading concentrations: a) absorbance of dyes at the peak wavelength and b) absorbance at $610 \mathrm{~nm}$; SiPc6 (orange triangles), SiPcBz6 (red circles), SiPcBz (blue inverse triangles), and no dye (black circles). 


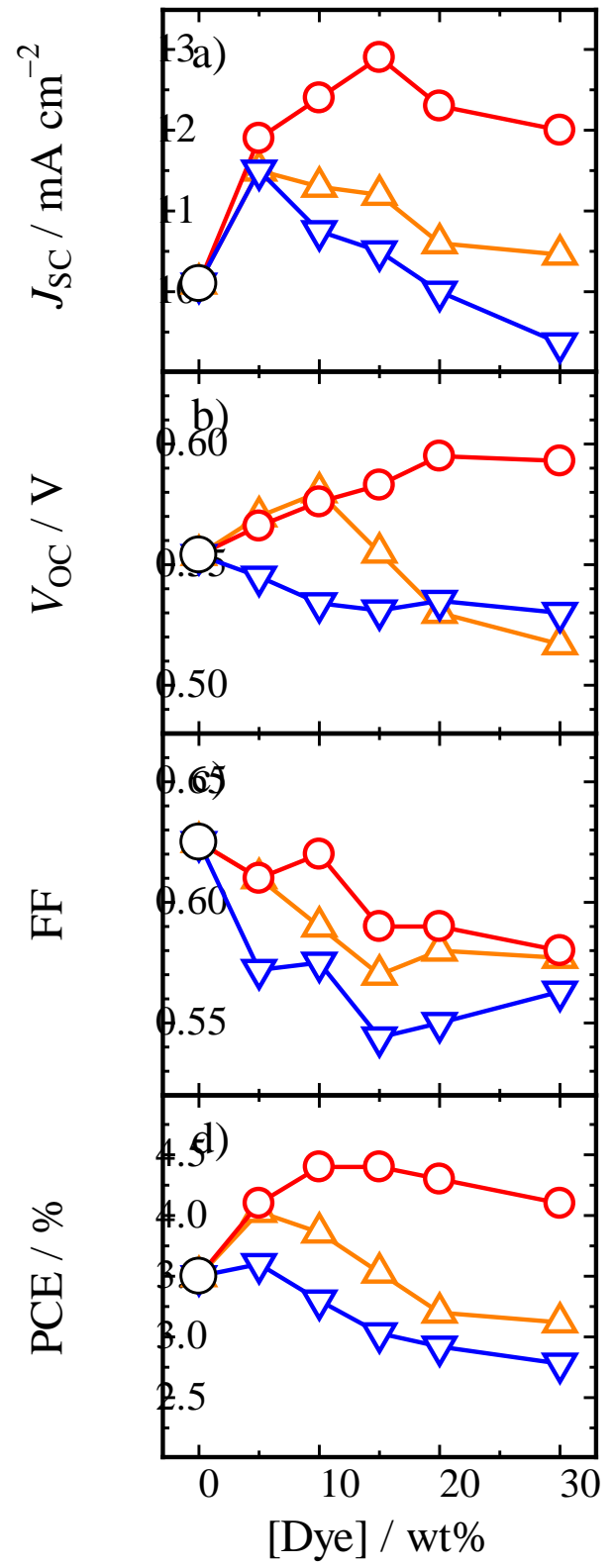

Figure 4. Photovoltaic parameters of P3HT/PCBM/SiPc ternary solar cells with different dye loading concentrations: a) short-circuit current density $\left(J_{\mathrm{SC}}\right)$, b) open-circuit voltage $\left(V_{\mathrm{OC}}\right)$, c) fill factor (FF), and d) power conversion efficiency (PCE); SiPc6 (orange triangles), SiPcBz6 (red circles), SiPcBz (blue inverse triangles), and no dye (black circles). These parameters are averaged for at least 18 devices. The error bars represent the standard deviation. 


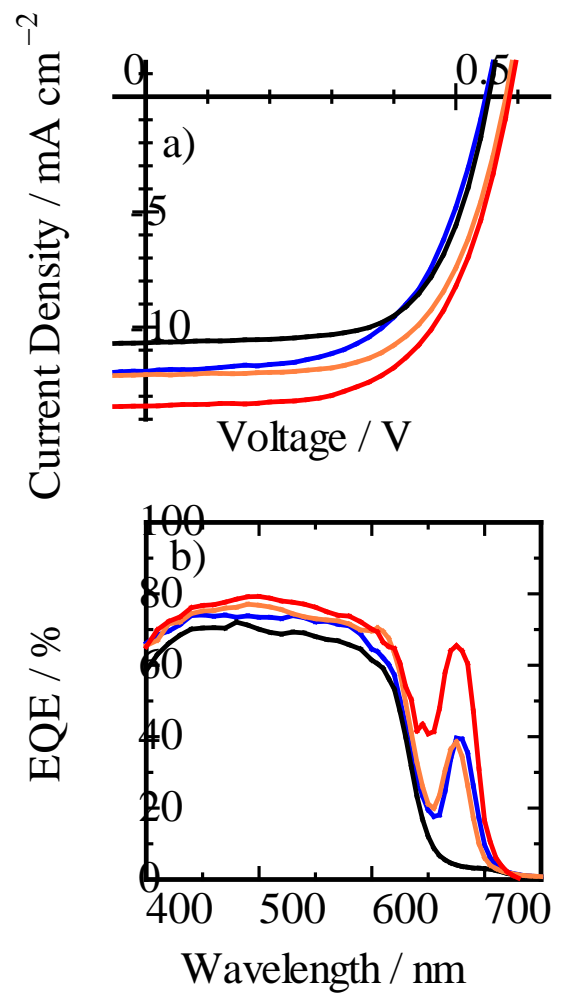

Figure 5. Best performance of ternary blend polymer solar cells employed in this work. a) $J-V$ characteristics and b) EQE spectra of P3HT/PCBM/SiPc ternary solar cells: SiPc6 (orange lines), SiPcBz6 (red thick lines), SiPcBz (blue lines), and no dye (black lines). The optimized dye concentration is $5 \mathrm{wt} \%$ (SiPc6), $15 \mathrm{wt} \%$ (SiPcBz6), and $5 \mathrm{wt} \%$ (SiPcBz). 
Table 1. Carrier lifetime in blend films.

\begin{tabular}{lcc} 
Blends & $\tau[\mu \mathrm{s}]^{\text {a) }}$ & $\tau_{\text {1sun }}[\mu \mathrm{s}]^{\text {b) }}$ \\
\hline P3HT/PCBM & 5.2 & 20.9 \\
P3HT/PCBM/SiPc6 & 11.1 & 36.3 \\
P3HT/PCBM/SiPcBz6 & 15.6 & 48.1 \\
P3HT/PCBM/SiPcBz & 7.0 & 21.4
\end{tabular}

a) carrier lifetime estimated by $\tau=(a \alpha)^{-1}$; b) carrier lifetime under the 1 Sun condition estimated by $\tau_{1 \text { sun }}=\tau n_{0} n_{1 \text { sun }}{ }^{-1}$ where $n_{1 \text { sun }}$ is set at $3 \times 10^{16} \mathrm{~cm}^{-3}$. ${ }^{45]}$ 


\section{WILEY-VCH}

Ternary blend polymer solar cells can be effectively improved by incorporating heterostructured near-IR dye, which has a hexyl group compatible with polymer and a benzyl group compatible with fullerene. Because of the compatibility with both materials, the heterostructured dye can be loaded up to $15 \mathrm{wt} \%$ and hence can boost the photocurrent generation by $30 \%$.

Keyword: interfaces, ternary blends, polymer solar cells, heterostructures, near-IR dyes

H. Xu, H. Ohkita, * Y. Tamai, H. Benten, S. Ito.

\section{Interface Engineering for Ternary Blend Polymer Solar Cells with Heterostructured Near-IR Dye}

ToC figure ((Please choose one size: $55 \mathrm{~mm}$ broad $\times 50 \mathrm{~mm}$ high or $110 \mathrm{~mm}$ broad $\times 20 \mathrm{~mm}$ high. Please do not use any other dimensions))

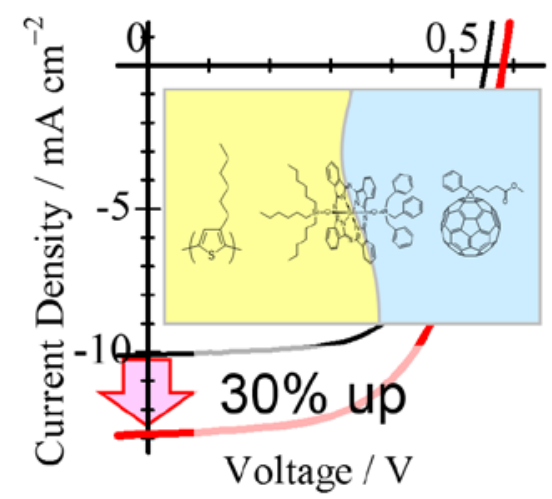

